\title{
The Collegiate Trainees Committee and the MRCPsych Examination
}

Since its inception in the late summer of 1979 the Collegiate Trainees Committee has devoted considerable time to discussing the present and future status and organization of the MRCPsych Examination. The following is a summary of the views of the Committee as collated by its Examination Working Party.

The CTC proposes that minor modifications to the present examination be undertaken in the short term and that consideration of the question of the future of the examination, with the possibility of more radical changes, be the remit of a working party to be set up by the Education Committee as soon as possible.

The minor modifications proposed are as follows:

1. The Preliminary Test should examine knowledge of basic clinical skills as well as basic sciences. This should be done by an MCQ and a series of short essays. The acquisition of clinical knowledge in the first year of psychiatric training must be seen to be important. Examining for clinical knowledge after one year may encourage trainees, consultants, clinical tutors and postgraduate course organizers to recognize this.

2. In the Membership Examination the interviewing skills of the candidate should be observed. This is a controversial issue which did not find favour in a consumer survey of trainees, (Bulletin, Jan 1981, p 8) and would be timeconsuming and expensive. Nevertheless the CTC feels this to be an essential part of the clinical examination. One sug- gestion is that a videotaped or audiotaped recording of the long case interview should be made available for assessment by the examiners.

3. The Membership Examination should include a series of videotaped short cases to be shown to the candidate, who would then answer questions in the form of short notes on the cases shown.

4. The Syllabus for the MRCPsych should be more detailed than at present.

5. Candidates who have failed (and possibly those who have passed) should receive more detailed feedback on their performance in the Preliminary Test and Membership Examination.

6. To aid in the standardization of the examination more training should be available to examiners, who should be chosen carefully and assessed for their skills in examining.

In the longer term the CTC would like to see the College explore the possibility of combining a more clinically biased Preliminary Test with a Diploma in Clinical Psychiatry. Other issues, such as the use of simulators as patients, continuous assessment during training and the submission of case reports by candidates, also deserve full consideration.

The changes proposed may incur expense, but this may be acceptable in the pursuit of a fairer and more valid test of psychiatric skills.

Carol Trotter

Member of CTC Working Party on Examinations

\section{Reviews}

Handbook for Inceptors and Trainees in Psychintry, edited by Thomas Bewley and Sasi Mahapatra. Royal College of Psychiatrists. 1980. £2.00.

Those who are concerned with trainees' matters at the College have not been idle over recent years; the second edition of this handbook is twice the size of the first. Much of the material in the first edition remains unchanged, largely because it consists of factual information concerning the constitution of the College and regulations for its examinations. The longest chapter remains that which lists the College committees - the list has increased with the addition of the new Trainees Committee.

Much of what is new, however, is relevant and helpful to new trainees in psychiatry. Ashley Robin's chapter on InService Training and Clinical Responsibility, for example, has been specially written as 'an immediate aid to new trainces' on the basis that it is best to do things properly from the beginning. This has not been the case for many trainees, and provided that tutors put this handbook (or something equivalent) in the hands of their SHO's on the first day in the specialty it will be a most useful contribution to the improvement of training. Similarly, the chapters that give hints on job hunting and coping with the MRCPsych examination (especially the examples of questions) will be much appreciated by many trainees.

However, in its attempts to be helpful the handbook runs into difficulty because of confusion within the College. On page 60 the hints on how to pass the examination describe the formulation in one way, but on page 61 it is described differently. This simply reflects the shoddy state of an examination which, after ten years, has still failed to describe clearly what is expected of candidates.

In many respects the official edicts of the College and other organizations do not fit nicely with the helpful chapters on how to cope with difficulties in training. This is just as if British Rail published with their timetable details of how to cope with train cancellations and delays! The official regulations (of both the DHSS and the College) concerning part- 
time training are clearly described. but a report from the working party states that their scheme is not being implemented in some parts of the country. Tutors' responsibility to the personal welfare of their trainees, especially doctors from overseas, are stressed; but it has been found necessary for the Handbook to include a section on culture shock and the overseas trainee because many tutors have not 'seen their trainees regularly on an individual basis' to appreciate this for themselves.

It is fine to read that the Approval Exercise can bring about 'dramatic and rapid improvement' in many training schemes and that there will be no dilution of the desired high standards (though with so few schemes failing to satisfy the Approval Panels one wonders how this can be so). But as if to contradict this statement, the editors have included an old set of examination results that demonstrates the high failure rate of overseas doctors working in mental hospitals compared with their UK counterparts holding posts in district general hospital units. This does not encourage overseas trainees and can contribute to their difficulties.

\section{Correspondence}

\section{An obstacle to in-patient treatment \\ DeAr Sir}

A recent experience has raised a problem which may have serious implications if it is widespread. I refer to the nonimplementation by social workers of medical recommendations under the Mental Health Act, 1959.

I was asked by a psychiatrically qualified prison medical officer to see a man soon to be released from prison following a short sentence for an act of apparently unprovoked violence. The medical officer thought that the man had paranoid schizophrenia and that he was not well enough to be discharged. This man was of no fixed bode, having left his home and employment some eighteen months previously, subsequently 'living rough'. I agreed with his diagnosis and we signed medical recommendations under Section 25 of the Act to commit him to my care in the adjoining hospital.

On the day of anticipated admission the prison medical officer telephoned me to say that the man had been released that morning because the social worker who had called to implement the order had disagreed and taken no action. The prison authorities had no alternative but to discharge the man into the community. I made a telephone call to the Area Officer concerned, but the Area Officer expressed extreme disinterest, and so I subsequently wrote to the Director of Social Services.

I received a courteous reply from the Director which, among other things, said that while the social worker must accept the medical diagnosis it was not the role of the social worker to 'act as a rubber stamp to medical decisions'.
This book should be read right through by every tutor, who should encourage his trainees to read and discuss it. Newcomers will need to be told, for example, whether to spend $£ 94.05$ or $£ 1.25$ on a psychiatric textbook and why their library does not take the 164 journals listed, without comment, in this publication. Such discussion will lead to the feedback the editors request.

Drs Bewley and Mahapatra are to be congratulated on bringing together these papers which individually read as satisfactory achievements but together highlight the very serious problems of training that have survived the first decade of the College's activities. Perhaps the new Trainees Committee can direct these activities more appropriately, as in the words of this Handbook the hope for the mental health services of the future rests on the quality of participating psychiatrists'.

University Hospital of South Manchester West Didsbury

Manchester M20 8LR
Francis Craed
Arrangements were made for the social worker to see me and discuss the reasons for his decision. This meeting did take place, but at the end of it I was really no wiser regarding his decision not to implement the recommendations. The patient involved has disappeared completely and all efforts by Social Services to trace him after release have failed.

Subsequent enquiries suggest that this is not an uncommon experience. A colleague at this hospital has had a very similar experience over a paranoid patient in the community in a neighbouring local authority area. General discussion at a recent conference suggested that many psychiatrists accept the situation by writing to the Social Services Department stating that they hold the Department responsible if anything goes wrong. This, I suggest, is not enough. Opinions I have canvassed are of the view that many social workers do not recognize psychotic illness when they meet it, and are not sufficiently trained to recognize many conditions. Some recognize it, but do not appear to have awareness of its serious implications if left untreated, and in some cases lack of action appears to be dictated by political ideological beliefs which override professional detachment.

If my experience is common, and I consider that the College should enquire into this, then patients are being put at risk of permanent defect, and the public in some cases is being put at unnecesary risk. If it is our general view that many social workers are not competent to exercise the duties now placed upon them under the Mental Health Act, 1959, we must say so clearly in the interests of mentally sick patients. With an inquiry taking place into the role of Social 